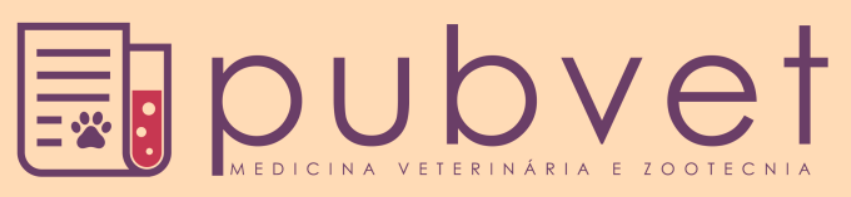

https://doi.org/10.22256/pubvet.v12n5a100.1-6

\title{
Análises físico-químicas e microbiológicas da água de bebedouros em escolas públicas da cidade de Timon-MA
}

\author{
Elisangela Miranda de Oliveira ${ }^{1 \bullet}$, Dalane Mendes Ribeiro ${ }^{1 \bullet}$, Maria Geci de Oliveira \\ Cronemberger $^{\circ}$, Wanderson Fiares de Carvalho $^{3 *} \bullet$, Maria Dulce Pessoa Lima ${ }^{4} \bullet$, \\ Kátia Regina Ferreira Sousa ${ }^{50}$
}

${ }^{I}$ Pós-Graduação em Controle de Qualidade de Alimentos do Instituto Federal de Educação, Ciência e Tecnologia do Piauí,. Teresina - PI Brasil. E-mail: elisangela_viver@hotmail.com

${ }^{2}$ Professora do Instituto Federal de Educação, Ciência e Tecnologia do Piauí-IFPI. Teresina - PI Brasil. E-mail: mariacronemberger@ig.com.br ${ }^{3}$ Professor do Instituto Federal de Educação, Ciência e Tecnologia do Piauí-IFPI, Valença do Piauí-PIBrasil. E-mail: wanderson.fiares@ifpi.edu.br ${ }^{4}$ Professora do Instituto de Ensino Superior Múltiplo - IESM. Timon-MA Brasil. E-mail: dulce.pl@ig.com.br

${ }^{5}$ Discente do Curso de Medicina Veterinária da Universidade Federal do Piaú, Teresina-PI Brasil. E-mail: katiafiares@outlook.com *Autor para correspondência

RESUMO. Objetivou-se com este estudo analisar os parâmetros físico-químicos e microbiológicos da água de 10 bebedouros utilizados para consumo em escolas públicas na cidade de Timon - MA a fim de verificar se as mesmas estão de acordo com os padrões de potabilidade estabelecidos pela legislação vigente. A água usada para fins de consumo que apresentam contaminações por microorganismos ou apresentam alterações nos padrões de qualidade fora do estabelecido pela legislação quando usada em excesso podem ser prejudiciais á saúde. As 10 escolas foram escolhidas aleatoriamente e as amostras coletadas em duas etapas das torneiras dos bebedouros, no horário da manhã, no qual foram recolhidas 10 amostras no total com interval de 15 dias. Os parâmetros analisados foram $\mathrm{pH}$, condutividade elétrica, dureza total, cloretos, cloro residual livre e análise microbiológica. Os resultados das amostras analisadas $\mathrm{pH}$, condutividade elétrica, dureza total e cloreto, apontaram que todas as águas possuem composição química dentro dos limites estabelecidos pela Portaria 2914 do Ministério da Saúde, exceto para concentrações de cloro residual livre em que $90 \%$ das amostras apresentaram teor de cloro residual fora dos padrões da legislação e quanto à análise microbiológica 30\% das amostras apresentaram coliformes totais. A ausência de higienização e monitoramento mais eficaz nestes estabelecimentos pode ter contribuído para a distribuição da água contaminada aos consumidores.

Palavras-chave: coliformes, condutividade, $\mathrm{pH}$

\section{Physicochemical and microbiological analysis of the water used for drinking fountains in public schools of the city of Timon-MA}

ABSTRACT. The objective of this study was to analyze the physicochemical and microbiological parameters of water from 10 drinkers used for consumption in public schools in the city of Timon - MA to verify if they are in accordance with the standards of potability established by the current legislation. Water used for consumer purposes that is contaminated by microorganisms or exhibits changes in quality standards that are not established by legislation when used in excess may be harmful to health. The 10 schools were randomly selected and the samples were collected in two stages of drinking taps in the morning, in which 10 samples were collected in total with a 15 days interval. The analyzed parameters were $\mathrm{pH}$, electrical conductivity, total hardness, chlorides, free residual chlorine and microbiological analysis. The results of the analyzed samples $\mathrm{pH}$, 
electrical conductivity, total hardness and chloride, showed that all the waters have chemical composition within the limits established by Ordinance 2914 of the Ministry of Health, except for concentrations of free residual chlorine in which $90 \%$ of the samples presented content of residual chlorine outside the standards of the legislation and for the microbiological analysis 30\% of the samples presented total coliforms. The absence of more effective sanitation and monitoring in these establishments may have contributed to the distribution of contaminated water to consumers.

Keywords: coliforms, conductivity, $\mathrm{pH}$

\section{Análisis físico-químicos y microbiológicos del agua de los bebederos en escuelas públicas de la ciudad de Timon-MA}

RESUMEN. Se objetivó con este estudio analizar los parámetros físico-químicos y microbiológicos del agua de 10 bebederos utilizados para consumo en escuelas públicas en la ciudad de Timón - MA a fin de verificar si las mismas están de acuerdo con los patrones de potabilidad establecidos por la legislación vigente. El agua utilizada para fines de consumo que presenta contaminación por microorganismos o presenta alteraciones en los patrones de calidad fuera de lo establecido por la legislación cuando se usa en exceso puede ser perjudicial para la salud. Las 10 escuelas fueron elegidas al azar y las muestras recogidas en dos etapas de los grifos de los bebederos, a la hora de la mañana, en el que se recogieron 10 muestras en total con intervalos de 15 días. Los parámetros analizados fueron $\mathrm{pH}$, conductividad eléctrica, dureza total, cloruros, cloro residual libre y análisis microbiológico. Los resultados de las muestras analizadas $\mathrm{pH}$, conductividad eléctrica, dureza total y cloruro, apunta que todas las aguas poseen composición química dentro de los límites establecidos por la Portaria 2914 del Ministerio de Salud, excepto para concentraciones de cloro residual libre en que el $90 \%$ de las muestras presentaron contenido de cloro residual fuera de los estándares de la legislación y en cuanto al análisis microbiológico el $30 \%$ de las muestras presentaron coliformes totales. La ausencia de higienización y monitoreo más eficaz en estos establecimientos puede haber contribuido a la distribución del agua contaminada a los consumidores.

Palabras clave: coliformes, conductividad, $\mathrm{pH}$

\section{Introdução}

A água usada para fins de consumo que apresentam contaminações por micro-organismo ou apresentam alterações físico-química e biológica fora do estabelecido pela legislação são fatores que preocupam, pois podem ser prejudiciais à saúde, tornando-a imprópria para o consumo. O Ministério da Saúde estabelece os procedimentos e responsabilidades que asseguram o controle de qualidade e distribuição da água para consumo humano que devem passar por etapas de tratamento de modo a cumprir rigorosamente com os padrões de potabilidade e de higiene.

Os bebedouros podem ser fontes favoráveis de contaminação se não forem devidamente higienizados, pois há contato direto entre pessoas com hábitos de higiene desconhecidos e se estes aparelhos não passarem por todas as etapas de tratamento que garantem o controle, qualidade e boas condições de uso, podem transmitir doenças causadas pelo consumo de água (Dantas et al., $\underline{2010)}$.

Os parâmetros que indicam o nível de qualidade da água são utilizados como indicadores para determinar possíveis alterações nas características físicas, químicas e biológicas que podem ser indesejáveis e prejudiciais para quem consome. Dentre os principais critérios que indicam impurezas e alterações encontradas na água temos os parâmetros físicos (temperatura), os parâmetros químicos $(\mathrm{pH}$, condutividade elétrica, dureza total, cloretos) e os parâmetros biológicos que são os coliformes termotolerantes e totais. Todos os parâmetros são regulamentados por normas e padrões estabelecidos pela Portaria $\mathrm{N}^{\circ}$ 2.914, de 12 de dezembro de 2011 do Ministério da Saúde que visam o controle de qualidade de uma forma segura sem oferecer riscos aos consumidores (Brasil, 2011).

Desta forma, objetivou-se com este estudo analisar os parâmetros físico-químicos e 
microbiológicos da água de 10 bebedouros utilizados para consumo em escolas públicas na cidade de Timon - MA a fim de verificar se as mesmas estão de acordo com os padrões de potabilidade estabelecidos pela legislação vigente.

\section{Material e Métodos}

O estudo foi desenvolvido na cidade de Timon - MA em 2014, no qual foram escolhidas 10 escolas públicas aleatoriamente e em cada colégio foram realizadas duas coletas dos mesmos bebedouros, com intervalo de 15 dias. A primeira coleta foi realizada nos dias 09 de setembro e a segunda coleta 24 de setembro. Nas escolas visitadas não há um monitoramento regular dos bebedouros quanto ao estado físico e higienização correta, o abastecimento dos bebedouros se dá por meio de poços tubulares e não há uma vistoria eficaz quanto ao estado físico, químico e microbiológico da água. As principais fontes destas águas destinadas ao consumo humano são oriundas do tratamento da empresa hídrica da cidade.

As análises das amostras das águas foram realizadas no laboratório do Instituto de Desenvolvimento do Piauí - IDEPI. Foram coletadas um total de 10 amostras dos bebedouros para a realização das análises dos parâmetros físico-químicos, em garrafas pet de $500 \mathrm{~mL}$ em temperatura ambiente e em condições normais e para análise microbiológica de coliformes totais foi utilizado sacos plásticos próprio para esse tipo de coleta com capacidade para $500 \mathrm{~mL}$ e mantidas sob refrigeração em caixa de isopor com gelo até o transporte ao laboratório de alimentos e microbiologia do Instituto Federal do Piauí - IFPI para início das análises. Os parâmetros analisados foram: $\mathrm{pH}$, condutividade elétrica, dureza total, cloretos, cloro residual livre e coliformes totais.

$\mathrm{O} \mathrm{pH}$ das amostras foi determinado por um pHmetro digital MOD. PHD10-PROCYON, através de leitura direta em potenciômetro; a condutividade elétrica foi feita por uma leitura direta utilizando-se o aparelho QUIMIS condutivimetro microprocessado - 0,00 a 19,999 $\mu \mathrm{s} \mathrm{cm}^{-1}$; A dureza total foi analisada pelo método volumétrico complexiométrico usando uma solução padrão de EDTA na presença de Negro de Ericromo T; o teor de cloreto foi usado o método de titulação com uma solução de nitrato de prata, precipitando o cloreto de prata, sendo o ponto final determinado com o indicador de cromato de potássio; o teor de cloro residual livre foi determinado através do Kit teste colorimétrico portátil pela comparação de cores com a escala padrão presente no frasco de coleta da água e a solução de orto-tolidina (reagente para cloro). Os procedimentos analíticos foram realizados conforme os métodos descritos no Standard Methods for the Examination of Water and Wastewater apud Funasa (2009).

$\mathrm{Na}$ determinação dos coliformes totais utilizou-se o Kit Colipaper que é uma cartela com meio de cultura em forma de gel desidratado usado para análise microbiológica que indica a presença ou ausência de coliformes totais. A cartela utilizada para fazer a análise microbiológica foi colocada num béquer de $100 \mathrm{~mL}$ contendo a mostra até ficar totalmente umedecida. Em seguida colocada dentro da embalagem de plástico e levada à estufa por 15 horas a temperatura de 36 $-37^{\circ} \mathrm{C}$.

\section{Resultados e Discussão}

Os resultados das análises da condutividade elétrica e do $\mathrm{pH}$ (Tabela 1) encontram-se com valores aceitáveis para consumo quando comparados dentro dos Valores Máximos Permitidos, segundo a Portaria 2914/11. De acordo com os resultados das análises da condutividade elétrica as amostras apresentaram níveis superiores a $200 \mu \mathrm{S} \mathrm{cm}^{-1}$, observou-se uma pequena variação nas amostras de cada bebedouro. Essa variação pode estar relacionada com a quantidade de íons dissolvidos, pois quanto maior a quantidade, maior será a condutividade e pode variar de acordo com a temperatura e o $\mathrm{pH}$. Todas as amostras de águas dos bebedouros apresentaram $\mathrm{pH}$ na faixa de 6,85 a 7,28 , encontrando-se, assim, dentro dos padrões estabelecidos.

Os resultados das análises de dureza total e cloreto (Tabela 2) encontram-se com valores aceitáveis para consumo quando comparados com os Valores Máximos Permitidos, segundo a Portaria 2914/11. Conforme os resultados das análises de dureza total de águas dos bebedouros, todos apresentaram valores menores que o limite máximo estabelecido para consumo humano que não deve passar de $500 \mathrm{mg} \mathrm{L} \mathrm{CaCO}$. A dureza de uma água é proporcional à presença de íons de cálcio e magnésio, podendo ser temporária ou permanente. Os resultados das amostras avaliadas em relação ao cloreto apresentaram valores dentro dos padrões máximos permitidos pela legislação. 
Tabela 1. Resultados das análises da condutividade elétrica e pH comparados com os Valores Máximos Permitidos segundo a Portaria 2914/11 do Ministério da Saúde.

\begin{tabular}{|c|c|c|c|c|c|c|c|}
\hline \multicolumn{4}{|c|}{ Condutividade Elétrica $\left(\mu \mathrm{S} \mathrm{cm}^{1}\right)$} & \multicolumn{4}{|c|}{$\mathrm{pH}$} \\
\hline \multirow{2}{*}{ Bebedouros } & \multicolumn{2}{|c|}{ Coletas } & \multirow{2}{*}{ - Desvio Padrão } & \multicolumn{2}{|c|}{ Coletas } & \multirow{2}{*}{ Desvio Padrão } & \multirow{2}{*}{$\begin{array}{c}\mathrm{VMP}^{*} \\
6,0-9,5\end{array}$} \\
\hline & $1^{\mathrm{a}}$ & $2^{\mathrm{a}}$ & & $1^{\mathrm{a}}$ & $2^{\mathrm{a}}$ & & \\
\hline 1 & 423,67 & 424,00 & 5,19 & 7,47 & 6,94 & 0,34 & Adequada \\
\hline 2 & 648,67 & 673,33 & 16,21 & 7,79 & 7,24 & 0,36 & Adequada \\
\hline 3 & 225,67 & 204,00 & 12,42 & 6,97 & 6,33 & 0,50 & Adequada \\
\hline 4 & 473,00 & 374,33 & 54,33 & 7,51 & 7,19 & 0,29 & Adequada \\
\hline 5 & 463,00 & 407,67 & 31,24 & 7,26 & 6,86 & 0,29 & Adequada \\
\hline 6 & 454,33 & 433,33 & 16,94 & 7,50 & 7,07 & 0,35 & Adequada \\
\hline 7 & 333,67 & 326,00 & 7,63 & 7,27 & 6,78 & 0,38 & Adequada \\
\hline 8 & 431,33 & 458,00 & 17,42 & 6,57 & 6,45 & 0,27 & Adequada \\
\hline 9 & 544,00 & 578,67 & 61,81 & 7,39 & 7,05 & 0,45 & Adequada \\
\hline 10 & 457,00 & 470,00 & 19,41 & 7,07 & 6,63 & 0,31 & Adequada \\
\hline Médias & 445,43 & 434,93 & 24,26 & 7,28 & 6,85 & 0,35 & Adequada \\
\hline
\end{tabular}

*VMP: Valor máximo permitido.

Tabela 2. Resultados das análises da dureza total e cloreto comparados com os Valores Máximos Permitidos segundo a Portaria 2914/11 do Ministério da Saúde.

\begin{tabular}{|c|c|c|c|c|c|c|c|c|}
\hline \multirow{3}{*}{$\begin{array}{l}\text { Locais de } \\
\text { Coleta }\end{array}$} & \multicolumn{4}{|c|}{ Dureza total $\left.(\mathrm{mg} \mathrm{L} \mathrm{CaCO})_{3}\right)$} & \multicolumn{3}{|c|}{ Cloreto (mg L) } & \multirow{3}{*}{$\begin{array}{c}\text { VMP* } \\
250\end{array}$} \\
\hline & \multicolumn{2}{|c|}{ Coletas } & \multirow{2}{*}{$\begin{array}{l}\text { Desvio } \\
\text { Padrão }\end{array}$} & \multirow{2}{*}{$\begin{array}{c}\text { VMP* } \\
500\end{array}$} & \multicolumn{2}{|c|}{ Coletas } & \multirow{2}{*}{$\begin{array}{l}\text { Desvio } \\
\text { Padrão }\end{array}$} & \\
\hline & $1^{\mathrm{a}}$ & $2^{\mathrm{a}}$ & & & $1^{\mathrm{a}}$ & $2^{\mathrm{a}}$ & & \\
\hline 1 & 63,00 & 65,00 & 1,63 & Adequada & 42,00 & 44,10 & 1,34 & Adequada \\
\hline 2 & 118,00 & 130,00 & 7,30 & Adequada & 52,50 & 53,90 & 1,14 & Adequada \\
\hline 3 & 59,50 & 46,00 & 7,89 & Adequada & 18,70 & 14,00 & 2,74 & Adequada \\
\hline 4 & 65,00 & 60,00 & 3,00 & Adequada & 48,30 & 39,20 & 5,53 & Adequada \\
\hline 5 & 67,00 & 62,00 & 3,42 & Adequada & 47,60 & 43,40 & 2,42 & Adequada \\
\hline 6 & 95,00 & 88,00 & 4,43 & Adequada & 33,60 & 36,40 & 1,98 & Adequada \\
\hline 7 & 61,00 & 64,00 & 1,91 & Adequada & 35,00 & 34,30 & 0,70 & Adequada \\
\hline 8 & 59,00 & 63,00 & 3,46 & Adequada & 47,60 & 47,60 & 0,00 & Adequada \\
\hline 9 & 92,00 & 100,00 & 4,90 & Adequada & 44,80 & 39,20 & 3,43 & Adequada \\
\hline 10 & 68,00 & 71,00 & 1,91 & Adequada & 47,60 & 47,60 & 1,14 & Adequada \\
\hline Médias & 74,75 & 74,90 & 3,99 & Adequada & 41,77 & 39,97 & 2,04 & Adequada \\
\hline
\end{tabular}

*VMP: Valor máximo permitido.

Dependendo da quantidade de cloreto na água pode apresentar sabor salgado que não é prejudicial para quem consome.

Os resultados das análises do cloro residual livre e dos coliformes totais (Tabela 3 ) encontramse com valores fora do padrão estabelecido para consumo quando comparados com a legislação. De todas as amostras analisadas de cloro residual livre, $10 \%$ apresentaram concentração de $0,5 \mathrm{mg}$ L que está dentro do padrão estabelecido e $90 \%$ das amostras estavam fora do padrão estabelecido, pois não apresentaram teor mínimo de $0,2 \mathrm{mg} \mathrm{L}$ considerável de cloro recomendado pelo Ministério da Saúde, demonstrando assim falhas no tratamento dessas águas destinadas ao consumo humano. O cloro é utilizado como agente de desinfecção da água que é suficiente para garantir a qualidade da mesma. Em relação às análises microbiológicas, $70 \%$ apresentaram ausência de coliformes totais e $30 \%$ demonstrou a presença de coliformes totais na água dos bebedouros avaliados, o que revelou uma contaminação localizada nas escolas. A presença de coliformes totais em água potável pode ser um indicador de contaminação relacionada a um tratamento mal realizado (Brasil, 2011).

Segundo o Ministério da Saúde os resultados das análises de coliformes totais, não podem apresentar nenhuma presença por $100 \mathrm{~mL}$ da amostra analisada. Dentre os 10 bebedouros 
analisados, $70 \%$ estavam dentro do padrão permitido e $30 \%$ encontram-se fora do padrão permitido.

Conforme a Portaria 2914/11 do Ministério da Saúde os parâmetros e suas características físicas químicas e biológicas, são utilizados como indicadores que asseguram o padrão de potabilidade, que tornam a água própria para consumo. Conforme os estudos de Oliveira et al. (2009) uma condutividade elevada com níveis superiores a $100 \mu \mathrm{S} \mathrm{cm}^{-1}$ indicam ambientes impactados e características corrosivas, observadas em poços. A baixa condutividade inferior a $200 \mu \mathrm{S} \mathrm{cm}-1$ pode indicar água potável por apresentar concentrações baixas de sais dissolvidos (Cetesb, 2009). No presente estudo os resultados das análises da condutividade elétrica apresentaram níveis superiores a $200 \mu \mathrm{S} \mathrm{cm}-1$, esses valores são aceitáveis para consumo das águas dos bebedouros.

Tabela 3. Resultados das análises do cloro residual livre e de coliformes totais comparados com os Valores Máximos Permitidos segundo a Portaria 2914/11 do Ministério da Saúde.

\begin{tabular}{lcccc}
\hline Parâmetro & (n) & Dentro do Padrão & Fora do Padrão & Legislação VMP* \\
\hline Cloro residual livre (mg/L) & 10 & $10 \%$ & $90 \%$ & $0,2-2,0$ \\
Coliformes totais (UFC/mL) & 10 & $70 \%$ & $30 \%$ & Ausência em $100 \mathrm{~mL}$ \\
\hline
\end{tabular}

*VMP: Valor máximo permitido.

A Portaria do Ministério da Saúde determina um intervalo de $\mathrm{pH}$ entre 6,0 a 9,5 para garantir a potabilidade. As águas naturais apresentam um $\mathrm{pH}$ entre 4 e 9, que pode ser influenciado pela dissolução de $\mathrm{CO}_{2}$, que origina baixos valores de pH. Quando o pH chega a 9, ocorre a retirada de gás carbônico (Brasil, 2011). Segundo Damasceno et al. (2010) em estudo realizado nas águas do rio Poty no Piauí, foi verificado $\mathrm{pH}$ variando de 7,26 a 7,76. Silva et al. (2009), encontrou valores de $\mathrm{pH}$ oscilando acima de 7 em reservatório da usina hidrelétrica de Peti em Minas Gerais. Santos \& Feliciano (2008) analisaram a dureza de poços no município de Ourinhos em São Paulo, onde verificaram a presença de água mole e dureza moderada. Segundo Silva et al. (2011) água com dureza menor que $50 \mathrm{mg} \mathrm{L} \mathrm{CaCO} 3$ é considerada água mole, entre 50 e $150 \mathrm{mg} \mathrm{L} \mathrm{CaCO} 3$ apresenta dureza moderada, entre 150 e $300 \mathrm{mg} \mathrm{L} \mathrm{CaCO} 3$ é água dura e maior que $300 \mathrm{mg} \mathrm{L} \mathrm{CaCO} 3$ é uma água muito dura. Duarte (2010) em estudos realizados na região do norte de Minas Gerais analisou águas subterrâneas alcalinas com alta dureza e variação de 150 a mais de 800 ppm em $\mathrm{CaCO} 3$, essas águas podem causar problemas no sistema de abastecimento. Silva et al. (2009) ao estudar águas de origem subterrânea em duas comunidades de Catolé do Rocha na Paraiba, observou valores de cloretos variando de 115 a $180 \mathrm{mg} \mathrm{L}$, valores acima de $250 \mathrm{mg} \mathrm{L}$ pode sofrer alterações nas características organolépticas (sabor). Na cidade de Francisco Beltrão no Paraná, foi analisada amostra de água das torneiras de laticínios, os resultados das análises de cloretos mostraram valores que variaram de $4,38 \mathrm{mg} \mathrm{L}$ a $24,84 \mathrm{mg} \mathrm{L}$, dentro do estabelecido pela legislação que é $250 \mathrm{mg}$ L (Brasil, 2011).
Ao analisar bicas nos municípios de Santos e São Vicente, Estado de São Paulo, Tavares et al. (2009) observaram que apenas duas bicas tinham suas águas tratadas com cloro residual e uma amostra apresentou o mínimo exigido pela legislação 0,2 mg L. De acordo com Grigoletto et al. (2012) a utilização de sais de hipoclorito durante o tratamento e desinfecção da água resulta no $\mathrm{pH}$ abaixo de 7. Chicati et al. (2010) verificou que a água consumida em região orizicola no Paraná, encontrava-se, de maneira geral, contaminada com coliformes totais e termotolerantes, sendo utilizados pela população e animais sem tratamento. $\mathrm{O}$ padrão microbiológico de potabilidade da água para consumo humano deve apresentar ausência de coliformes totais, termotolerantes ou Escherichia coli em $100 \mathrm{~mL}$ de água (Brasil, 2011).

Ao analisar água de bebedouros do Campus Universitário de Ipatinga em Minas Gerais, Carvalho et al. (2009) encontrou resultado insatisfatório para bactérias heterotróficas, impróprias para o consumo humano. Chaves et al. (2010) analisou águas de poços artesianos de 10 laticínios da cidade de Rio Pomba em Minas Gerais, sem nenhum tipo de tratamento, onde duas amostras estavam dentro dos padrões de potabilidade. A presença de coliformes termotolerantes é um indicador de contaminação fecal ligado a tratamento inadequado ou ineficiência da desinfecção da mesma (Brasil, 2011).

\section{Conclusão}

De acordo com os resultados obtidos, pode-se concluir que os valores máximos permitidos para 
as análises do $\mathrm{pH}$, condutividade elétrica, dureza total e cloreto estão dentro dos padrões de qualidade para consumo humano, segundo a Portaria 2914/2011 do Ministério da Saúde, exceto os resultados do cloro residual livre e da analise microbiológica que apresentaram valores fora dos padrões estabelecidos pela legislação. A ausência de higienização e monitoramento mais eficaz nestes estabelecimentos pode ter contribuído para a distribuição da água contaminada aos consumidores.

\section{Referências bibliográficas}

Brasil, M. d. S. 2011. Portaria No 2.914, de 12 de dezembro de 2011. Dispõe sobre os procedimentos de controle e de vigilância da qualidade da água para consumo humano e seu padrão de potabilidade. Diário Oficial da União.

Carvalho, D. R., Fortunato, J. N., Vilela, A. F. \& Badaró, A. C. L. 2009. Avaliação da qualidade físico-química e microbiológica da água de um campus universitário de Ipatinga-MG. NUTRIR GERAIS-Revista Digital de Nutrição, Ipatinga, 3(5), 417-427.

Cetesb, C. A. d. E. d. S. P. 2009. Qualidade das Águas Interiores no Estado de São Paulo

Chaves, K. F., da Silva, N. B. N., Vieira, T. B., Mendes, A. C. G., Gravina, C. S., de Oliveira Martins, A. D. \& Martins, M. L. 2010. Avaliação Microbiológica da Água Empregada em Laticínios da Região de Rio Pomba-MG. UNOPAR, 12(4), 5-8.

Chicati, M. L., Nanni, M. R. \& Cezar, E. 2010. Indicadores físico-químicos e bacteriológicos da qualidade da água para consumo humano e animal em área orizicola irrigada. Agropecuária Técnica, 31(2), 126-133.

Damasceno, L. M. O., Andrade Júnior, A. S., Dias, N. S., Franco, J. L. D. \& Silva, E. F. F. 2010. Aspectos qualitativos da água do Rio Poty na região de Teresina, Piauí. Revista Ciência Agronômica,, 41, 139-148.

Dantas, A. K. D., Souza, C., Ferreira, M. S., Andrade, M. A., Andrade, D. \& Watanabe, E. 2010. Qualidade microbiológica da água de bebedouros destinada ao consumo humano. Revista Biociências, 16(2).
Duarte, F. V. 2010. Influência da aplicação de gás carbônico na redução de precipitação de carbonatos em sistema de irrigação localizada.

Funasa, F. N. d. S. 2009. Manual prático de análise de água. 3.Ed. Brasília: Fundação Nacional de Saúde.145p.

Grigoletto, T. L. B., Fuzari, B. H. C., Andrade, A. R. d., Campos, M. L. A. d. M., Gerlach, R. F. \& Santos, J. E. T. 2012. Fatores químicos e físicos que afetam a contaminação por chumbo e cobre em água potável: uma abordagem para o estudo de caso em química analítica. Química Nova, 35(10), 1995-2001.

Oliveira, A. S., Almeida, A. G., Sgrignolli, L. A., Otoboni, A. M. M. B. \& Marinelli, P. S. 2009. Levantamento físico-químico e higiênicosanitário de águas de irrigação do cultivo de hortaliças na cidade de marília/SP.

Santos, F. G. \& Feliciano, S. 2008. Determinação da Dureza Total de Água de Poços Artesianos no Município de Ourinhos - SP. In: VII Congresso de Iniciação Cinetífica, 2009, Ourinhis. Anais do VII Congresso de Iniciação Cinetífica, 1, 1-246.

Silva, A. P. S., Dias, H. C. T., Bastos, R. K. X. \& Silva, E. 2009. Qualidade da água do reservatório da Usina Hidrelétrica (UHE) de Peti, Minas Gerais. Revista Árvore, 33(6).

Silva, I. N., Fontes, L. O., Tavella, L. B., Oliveira, J. B. \& Oliveira, A. C. 2011. Qualidade de água na irrigação. Agropecuária Científica no SemiÁrido, 7(3), 1-15.

Tavares, D. S., Alonso, A. C. B., de Mello, A. R. P., de Sousa, C. V., Gonzalez, E., de Camargo Passos, E., . . . Barsotti, R. C. F. 2009. Qualidade da água de bicas localizadas nos municípios de Santos e São Vicente, Estado de São Paulo, Brasil. Revista do Instituto Adolfo Lutz, 68(2), 237-244.

Article History:

Received 22 January 2018

Accepted 2 March 2018

Available online 11 May 2018

License information: This is an open-access article distributed under the terms of the Creative Commons Attribution License 4.0, which permits unrestricted use, distribution, and reproduction in any medium, provided the original work is properly cited. 